\title{
Immobilization of Lactic acid bacteria for production of extracellular polysaccharides
}

\author{
Jing $\mathrm{TAO}^{1,2 *}$ (D), Xiaohui HUANG ${ }^{3}$, Feiyue $\mathrm{LING}^{1}$, Bilian YU ${ }^{1}$, Xiao ZHOU${ }^{1}$, Qing SHEN ${ }^{1}$, Gianni SAGRATINI²
}

\begin{abstract}
Lactic acid bacteria (LAB) can produce extracellular polysaccharides that can be used as thickeners, emulsifiers, and gels in foods. The immobilization technology can effectively simplify and improve the separation and regeneration of extracellular polysaccharides. In this study, six strains of LAB, including the extracellular polysaccharide-producing strain Lactobacillus plantarum, were screened. The different immobilized carriers of sodium alginate, agar, gelatin-glutaraldehyde, and carrageenan were assessed for fermentation by these six LAB. Different diameters of beads were selected, and the optimum culture temperature, carrier concentration, and inoculum volume were evaluated. The results showed that the agar-embedding method was the best immobilization method and the optimum process conditions were as follows: $3 \%$ inoculum of $L$. plantarum, $30 \mathrm{~g} / \mathrm{L}$ of agar as immobilization carrier with a particle diameter of $1 \mathrm{~cm}$, and fermentation at $37^{\circ} \mathrm{C}$ for $24 \mathrm{~h}$. Through orthogonal experiments, the maximum exopolysaccharide (EPS) yield obtained was $1489.9 \mathrm{mg} / \mathrm{L}$.
\end{abstract}

Keywords: Lactic acid bacteria; extracellular polysaccharide; immobilized cell; biological microcapsule.

Practical Application: The immobilization technology can effectively simplify and improve the separation and regeneration of extracellular polysaccharides. The study provides a basis for improving the separation and regeneration performance of EPS and continuous fermentation to produce LAB EPS. Moreover, the immobilized LAB cells can be well maintained and can be used repeatedly, effectively increasing the rate of use of the strain and reducing the production cost.

\section{Introduction}

The Lactic acid bacterial exopolysaccharides (LAB EPS) are either loosely bound to the cell surface or released into the surrounding environment during growth (Abedfar \& Hossininezhad, 2016; Darilmaz \& Beyatli, 2012; Deepak et al., 2016; Patel et al., 2012; Saadat et al., 2019). Among the various EPS producing bacteria, LAB have gained special attention (Kleerebezem et al., 2017; Riaz et al., 2015; Sanalibaba \& Çakmak, 2016). LAB are generally recognized as safe microorganisms and produce EPS with a wide diversity of structures with no health risk (Surayot et al., 2014; Thummar \& Ramani, 2016; Ryan et al., 2015). EPS produced by LAB have recently received increasing attention because of their health benefits to the consumers (Ishiguro et al., 2017; Mejia-Gomez \& Balcázar, 2020). EPS produced by LAB possess various potential health benefits and have important functional roles in human or animal health including immunomodulatory properties, anti-cancer, antioxidant activity, anti-ulcer (Abid et al., 2018; Deepak et al., 2016; Zhang et al., 2015), anti-biofilm agents to prevent adhesion of pathogenic bacteria, blood glucose (Oleksy \& Klewicka, 2018; Kanak \& Yilmaz, 2021; Pato et al., 2021) and cholesterol lowering properties (Korcz et al., 2018), and antihypertensive activity (Harutoshi, 2013). Although some EPS form biofilms that cause hygiene problems, other EPS derived from $\mathrm{LAB}$ play a crucial role in improving the rheology, texture, and mouthfeel of fermented food formulations in the food industry (Dilna et al., 2015; Lee et al., 2011).
The production of LAB EPS is affected by many environmental factors and intracellular factors. LAB secrete different types of EPS (Miao et al., 2015). Important factors for the total yield of EPS produced from LAB include the composition of the medium (carbon and nitrogen sources, vitamins, minerals, etc.), LAB strains, and growth conditions (temperature, agitation, incubation time, $\mathrm{pH}$, and oxygen tension). One of the main disadvantages of the EPS-producing LAB is the small amount of polymer synthesized, which varies from $25-500 \mathrm{mg} / \mathrm{L}$. The highest production levels reported so far were obtained for the mesophilic strains Lactobacillus rhamnasus $9595 \mathrm{M}(1200 \mathrm{mg} / \mathrm{L})$ and Lactobacillus sakei 0-1 (1375 mg/L) (Mozzi et al., 2003). Optimization of the growth environment is critical if maximal EPS production by LAB strains is to be achieved (Patel et al., 2012). To produce EPS using the biological microcapsule, the cells are evenly dispersed in the gel beads, which can maintain the viability and intracellular enzyme activity of the bacteria for a long time, for continuous production, and protect the cells from adverse conditions such as acid, alkali, and harmful ions. Immobilized particles are also conducive to simple strain activation and product extraction process (Miao et al., 2015). Continuous fermentation of immobilized (Menchavez \& Ha, 2019; El-Dalatony et al., 2016; Eş et al., 2018) LAB to produce EPS can simplify and optimize the industrial production process (Caggianiello et al., 2016; Thakur et al., 2019), which can substantially reduce production costs (Idris \& Suzana, 2006). The excessive production cost of LAB EPS also

Received 02 Oct., 2021

Accepted 08 Nov., 2021

${ }^{1}$ School of Food and Bioengineering, Zhengzhou University of Light Industry, Zhengzhou, Henan, China

${ }^{2}$ School of Pharmacy, University of Camerino, Camerino, Italy

${ }^{3}$ School of Bioscience and Veterinary Medicine, University of Camerino, Camerino, Italy

*Corresponding author: taojing@zzuli.edu.cn 
restricts its large-scale industrial production. However, there is no research on the immobilization of lactic acid bacteria to produce exopolysaccharides.

In this study, high-yielding EPS LAB strains were firstly screened, immobilized, and used for shake flask fermentation. The optimized immobilization method, fermentation production temperature, and seed access amount were selected, and orthogonal experiments were carried out to determine the optimized immobilized LAB EPS fermentation process conditions. The study provides a basis for improving the separation and regeneration performance of EPS and continuous fermentation to produce LAB EPS.

\section{Materials and methods}

\subsection{Material}

Six strains of LAB, Lactobacillus bulgaricus 1.6970(CGMCC), Lactobacillus acidophilus 1.1878(CGMCC), Lactobacillus plantarum GIM1. 191 (GIMCC), Streptococcus thermophilus 1.2718(CGMCC), Lactobacillus casei 1.3206(CGMCC), and Lactococcus lactis subsp.latis 6242 LL9(CICC) were provided by Laboratory of College of Food and Bioengineering, Zhengzhou University of Light Industry. The dialysis bag treatment solution consisted of solution A (1.6 g of sodium hydrogen carbonate and $0.296 \mathrm{~g}$ of EDTA dissolved together in $800 \mathrm{~mL}$ of distilled water) and solution B (0.298 g of EDTA dissolved in $800 \mathrm{~mL}$ of distilled water).

\subsection{Strain activation}

The bacterial powder was inoculated into MRS liquid medium, cultured at $37^{\circ} \mathrm{C} 24 \mathrm{~h}$, subcultured 2 to 3 times, and stained for microscopic examination. The selected excellent strains were transferred to MRS slants and stored in a refrigerator at $4{ }^{\circ} \mathrm{C}$ for use.

\subsection{Microbial cell fixation:}

\section{Calcium alginate method}

The logarithmic growth phase fermentation solution was centrifuged, and a cell suspension was prepared with an equal volume of normal saline. Ten milliliters of the bacterial suspension was added into a defined concentration of immobilized carrier solution (alginic acid sodium solution). After mixing, granulation was carried out with a syringe by dropping $2 \%$ calcium chloride solution and immobilized for 1.5 2 $\mathrm{h}$.

\section{Agar fixation method}

The melted agar solution (3\%) was mixed with the logarithmic growth phase fermentation broth using a syringe to drop the mixture into a measuring cylinder containing liquid paraffin in the upper layer and the lower layer was water. The granules were filtered using sterile gauze and rinsed three times with sterile water for further use.

\section{Gelatin-glutaraldehyde fixation method}

The gelatin solution and the logarithmic growth phase fermentation broth were uniformly mixed to obtain the final gelatin concentration of $10 \%$. To the mixture, glutaraldehyde was directly added, stirred uniformly, and poured into a sterilized culture dish. After coagulation, the gel was cut into small squares of $5 \mathrm{~mm} \times 5 \mathrm{~mm} \times 5 \mathrm{~mm}$ and rinsed with sterile water for use.

\section{Carrageenan embedding method}

Carrageenan is highly stable as fine powder and does not hydrolyze even when heated. $4 \mathrm{~g}$ carrageenan was poured at $8 \%$ concentration into $50 \mathrm{~mL}$ distilled water and shaken. This was disinfected and dissolved in a sterilizer and allowed to cool. After cooling to about $45^{\circ} \mathrm{C}$, the mixed bacterial suspension was embedded.

\subsection{Determination of EPS using the phenol sulfuric acid method}

Pure glucose (4 mg) was dissolved in double-distilled water, quantitatively transferred to a $100 \mathrm{~mL}$ volumetric flask, diluted with double-distilled water to the container mark line, and shaken well to obtain a final concentration of $40 \mu \mathrm{g} / \mathrm{mL}$ glucose.

Standard samples of different concentrations were prepared in $820 \mathrm{ml}$ fixed tubes. The absorbance was determined by phenol sulfuric acid method with 0 tube solution as reference. The standard curves of glucose solution with different concentrations were obtained.

\subsection{MD34 dialysis bag treatment and use method}

Pretreatment of dialysis bag (first use) was done by cutting at a length of $15 \mathrm{~cm}$, and the cut dialysis bag was boiled in deionized water for $10 \mathrm{~min}$.

Then the dialysis bag was treated by washing the used dialysis bag with deionized water, and the washed dialysis bag was boiled in solution A for $10 \mathrm{~min}$, taken out, and washed with deionized water. The dialysis bag was then boiled in solution $B$ for $10 \mathrm{~min}$, washed with deionized water, and finally stored in $20 \%$ ethanol at $4{ }^{\circ} \mathrm{C}$ or used directly.

The beaker was filled with $800 \mathrm{~mL}$ of double-distilled water, and one end of the treated dialysis bag was clamped with a dialysis clip, and then double-distilled water was charged to check for water leakage (including whether the clip was caught or the dialysis bag was damaged). After the leak detection was completed, the bag was marked with a black marker on the clip, and 20 times diluted EPS solution was added to the dialysis bag and checked for leaks again. After confirming the error, dialysis was carried out for $12 \mathrm{~h}$.

\subsection{Dialysate post-treatment}

The dialyzed dialysate was poured into a sterile test tube and a number was assigned to it.

To a corresponding number of sterile test tubes, $1 \mathrm{~mL}$ of the treated dialysate was added separately, and $2 \mathrm{~mL}$ of double- 
distilled water was added to one of the tubes numbered 0 , as a blank control experiment. Then, to each tube, $1 \mathrm{~mL}$ of deionized water followed by $1 \mathrm{~mL}$ of $5 \%$ phenol solution, and $5 \mathrm{~mL}$ of $95 \%$ concentrated sulfuric acid were added to each tube and allowed to stand for $10 \mathrm{~min}$. Finally, EPS was determined by the phenol sulfuric acid method.

\subsection{Optimization of protein removal conditions}

The polysaccharide purification process involves the removal of impurities from the extracted crude polysaccharide so that a single polysaccharide component can be obtained. The main impurities in the LAB EPS are proteins, pigments, and some small molecules, which make it difficult for the subsequent extraction of EPS. Therefore, the key point of purifying the LAB fermentation broth is the removal of proteins. For this, the trichloroacetic acid solution was added at a one-fifth volume of the fermentation broth, shaken well, and placed at $4{ }^{\circ} \mathrm{C}$ for $12 \mathrm{~h}$ to settle.

\subsection{Experimental procedure}

The process flow chart of EPS separation and purification is shown in Figure 1.

\section{Results and discussion}

\subsection{Preparation of a standard curve}

The absorbance (OD) of the sample was measured at $490 \mathrm{~nm}$ using a spectrophotometer. The standard glucose quasi-curve was prepared by taking the liquid in tube number 0 (blank) as a reference, the glucose concentration as the abscissa, and the corresponding OD value as the ordinate. The linear regression equation $\mathrm{y}=0.0095 \mathrm{x}-0.0067$ and the correlation coefficient $\mathrm{R}^{\wedge} 2=0.9955$ were obtained.

\subsection{Screening of extracellular polysaccharide produced by $L A B$}

If the EPS produced by LAB cells is widely used, the first task in actual production is to obtain EPS high-yielding strains to reduce EPS production costs. In this experiment, the EPS producing ability of six strains of LAB was studied, and high
EPS-yielding strains were screened. For each LAB, 5\% inoculum was fermented in MRS medium for $24 \mathrm{~h}$, and the EPS yield was measured after extraction and purification. The results are shown in Figure 2.

According to Figure 2 that the six strains of LAB can synthesize EPS, but at different capacities. The highest production EPS was by L. plantarum at $1513.1 \mathrm{mg} / \mathrm{L}$, and the lowest yield was by cheese $\mathrm{LAB}$, L c casei at $1064.6 \mathrm{mg} / \mathrm{L}$. The EPS production by the other five strains was somewhere in between. L. plantarum was identified as a high EPS producing strain (Imran et al., 2016; Lee et al., 2016).

\subsection{Single-factor impact experiment}

Effect of immobilized materials on the production of extracellular polysaccharides by L. plantarum

L. plantarum was immobilized in four different carrier types, with $5 \%$ inoculum, and fermented in a shake flask at $37^{\circ} \mathrm{C}$. Then EPS extraction and purification were conducted, and finally, the EPS yield was measured by a spectrophotometer.

The bar graph (Figure 3a) shows that the EPS yield of L. plantarum decreased after treatment with immobilized materials, and the agar embedding method had the highest EPS productivity by L. plantarum, which was $1096.2 \mathrm{mg} / \mathrm{L}$; therefore, agar was selected as the immobilization material to further explore the optimum process conditions.

\section{Effect of temperature on the content of extracellular} polysaccharides by L. plantarum

Immobilization of microorganisms sometimes changes their optimum temperature of the fermentation. Generally, the optimum temperature of the immobilized enzyme is higher than that of the free enzyme, so the optimum fermentation temperature also increases. We investigated the optimal temperature of EPS synthesis after immobilizing microbial cells. The EPS yield measured after fermentation of immobilized L. plantarum at different temperatures is shown in Figure $3 \mathrm{~b}$.

As can be seen from the Figure $3 \mathrm{~b}$, the optimum temperature for fermentation of immobilized L. plantarum was $37^{\circ} \mathrm{C}$. When

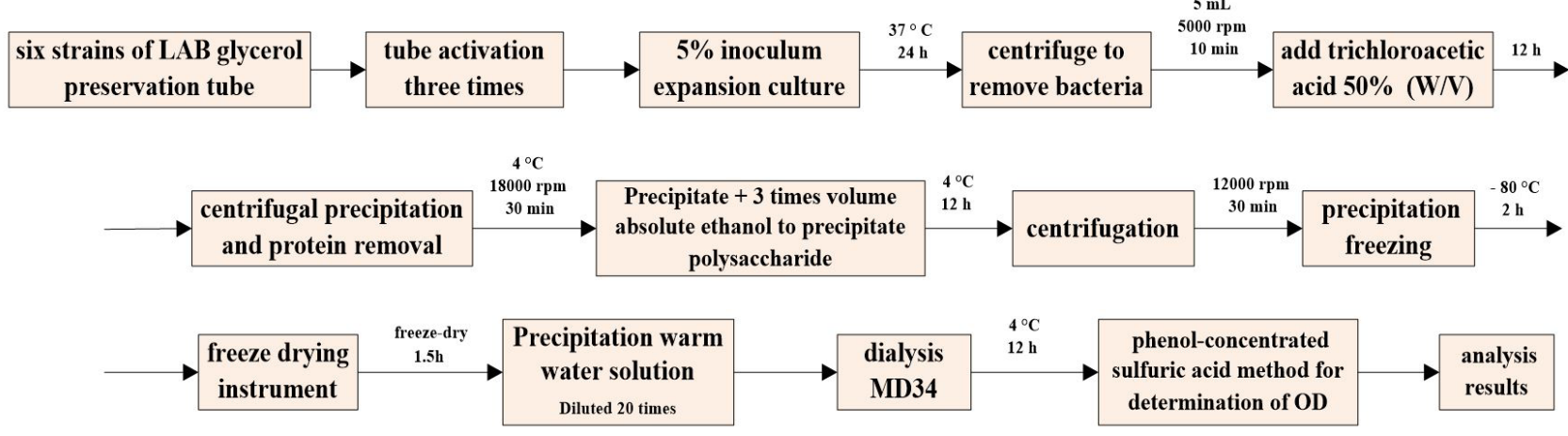

Figure 1. Process flow chart of EPS separation and purification. 


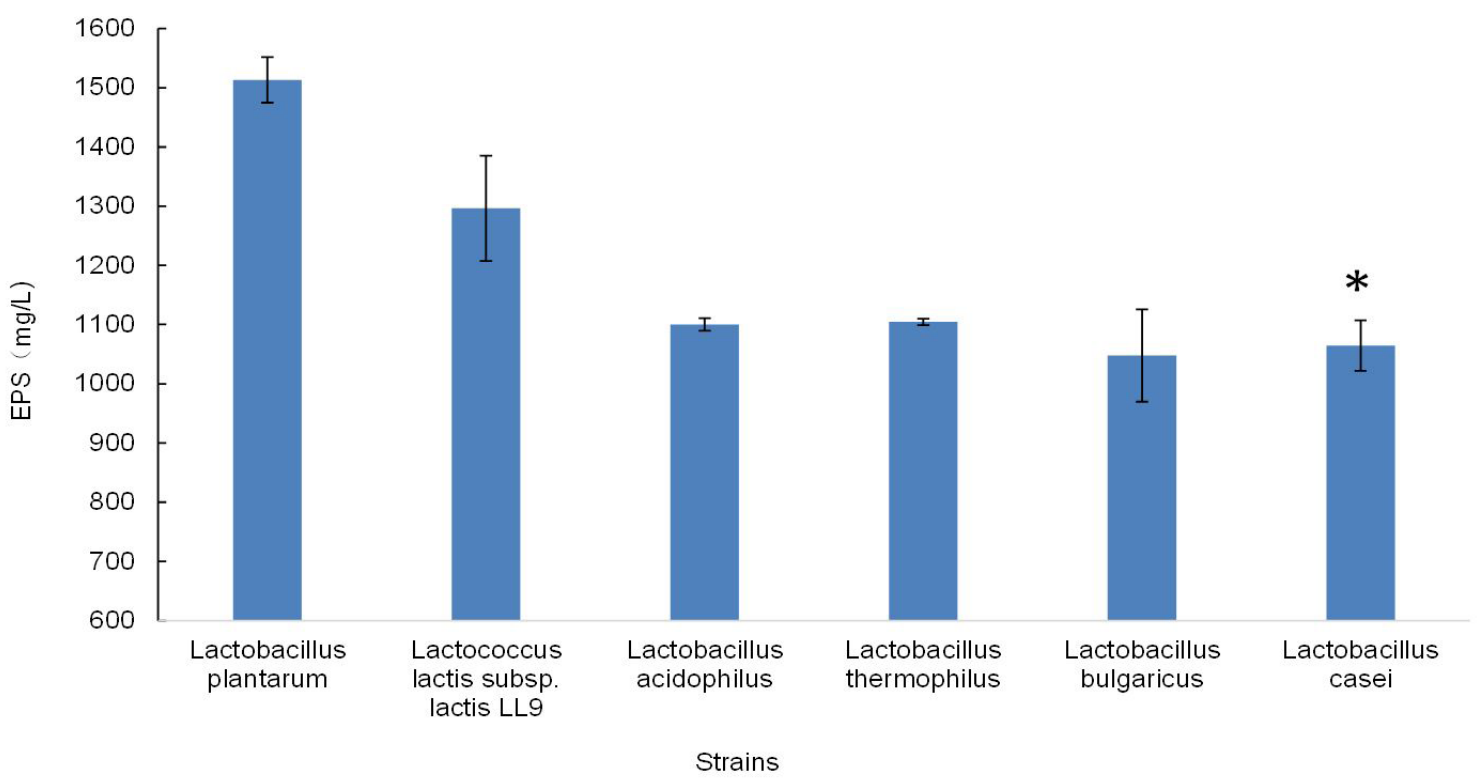

Figure 2. Screening of high-yielding EPS strains of lactic acid bacteria at $5 \%$ inoculum each. Significant differences $(p<0.05)$ between the two experimental samples are indicated by the asterisk.

the fermentation temperature was lower than $37^{\circ} \mathrm{C}$, the EPS yield reduced significantly and was the lowest at $30^{\circ} \mathrm{C}$. The results showed that the optimum temperature of fermentation for maximum yield of EPS by $L$. plantarum did not change, and was $37^{\circ} \mathrm{C}$.

Effect of amount of inoculum on the production of extracellular polysaccharides by L. plantarum

Microorganisms require optimal inoculum for fermentation and productivity. A very large or very small size of inoculum affects product synthesis. Here, we studied the effect of different amounts of inoculum $(15 \%, 13 \%, 10 \%, 8 \%$, and $5 \%)$. The effect of inoculum size on the production of EPS by L. plantarum is shown in Figure 3c.

As can be seen from Figure $3 c$, when the inoculum amount was $5 \%$, the EPS yield of LAB was the highest at $1443.6 \mathrm{mg} / \mathrm{L}$, indicating that the inoculation amount was optimal and the most beneficial for the production of EPS by LAB fermentation.

\section{Effect of immobilization using agar at different concentrations on the production of extracellular polysaccharides by L. plantarum}

The concentration of agarose for immobilization can have a significant impact on EPS yield. A low concentration of agar results in low strength of the colloid after embedding, causing brittleness and affecting dispersibility, and a possible cell leakage leading to embedding failure. At high agarose concentration, the agar colloid strength is not easy to break, but it affects the contact efficiency between the nutrient and the bacteria, causing slow growth of the cells, and a decrease in the efficiency of EPS productivity. Moreover, the EPS cannot diffuse into the fermentation broth through the agar, and little or no detection is detected in the fermentation broth, thus, greatly affecting the yield of LAB EPS. We studied the effect of different concentrations of agar $(15,20,25,30$, and $35 \mathrm{~g} / \mathrm{L})$. The effect of agar concentration on EPS production by L. plantarum is shown in Figure 3d.
When the agar concentration was $35 \mathrm{~g} / \mathrm{L}$, the LAB EPS yield was $1458.3 \mathrm{mg} / \mathrm{L}$. This indicates that the agar strength does not significantly affect the LAB EPS productivity of L. plantarum and the culture solution. It does not affect the absorption of nutrients by the cells, as well as the diffusion of EPS into the medium solution. Therefore, the agar concentration of $35 \mathrm{~g} / \mathrm{L}$ was selected as the optimum colloid strength.

\section{Effect of the diameter of agar particle on the production of extracellular polysaccharides by L. plantarum}

The size of the encapsulated agar block has a large effect on the EPS yield of $L$. plantarum. Excessively large size is not conducive to the exchange of substances between the LAB and the medium and is too small to be conducive to experimental operation and actual fermentation production. Here, we tried the beads of the immobilized carrier material at different sizes $(5,10$, and $15 \mathrm{~mm})$ and the effect on EPS production is shown in Figure 3e.

When the agar particle diameter was $1.0 \mathrm{~cm}$, the EPS yield of L. plantarum was $1477.3 \mathrm{mg} / \mathrm{L}$ and the highest among all the tested agar particles of different diameters. This indicates that the microorganisms embedded in the agar can exchange materials with the medium and that the effect of agar immobilization on LAB EPS productivity was minimal. Therefore, $1.0 \mathrm{~cm}$ was selected as the optimum particle size for immobilization.

\subsection{Orthogonal experimental results}

From the afore-mentioned single factor experiments, three conditions of fermentation temperature, agar strength, and inoculum size could be selected for the orthogonal experiment (Table 1).

The results of the orthogonal experiment are shown in Table 2.

The analysis of the R-value from the orthogonal experiments shows that the influence of a single factor on the EPS yield 
a
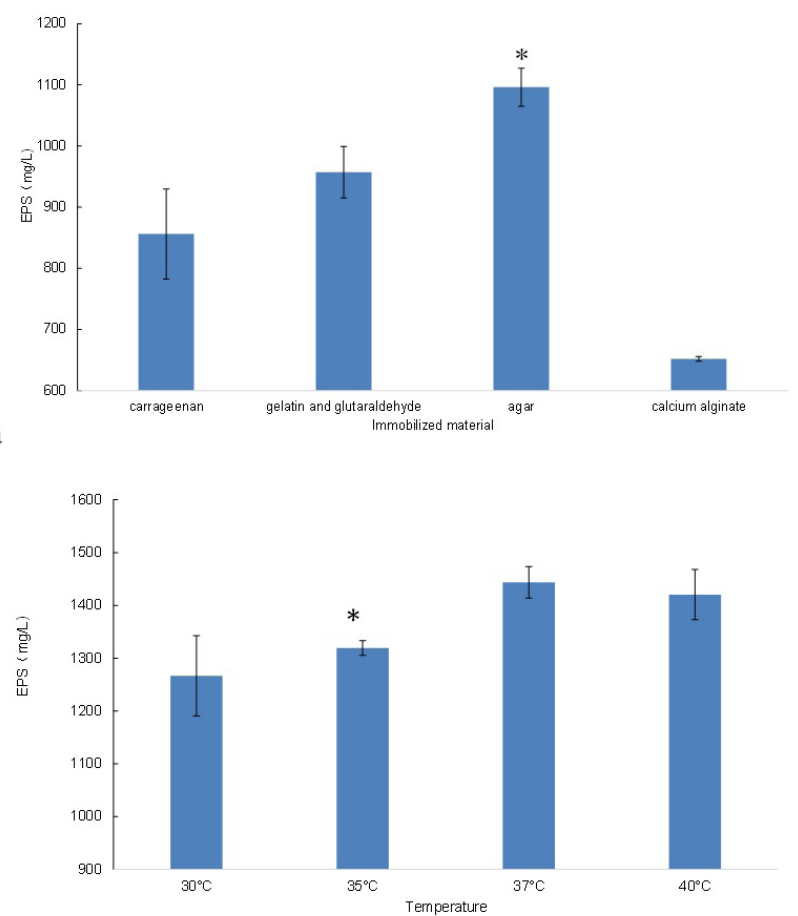

b
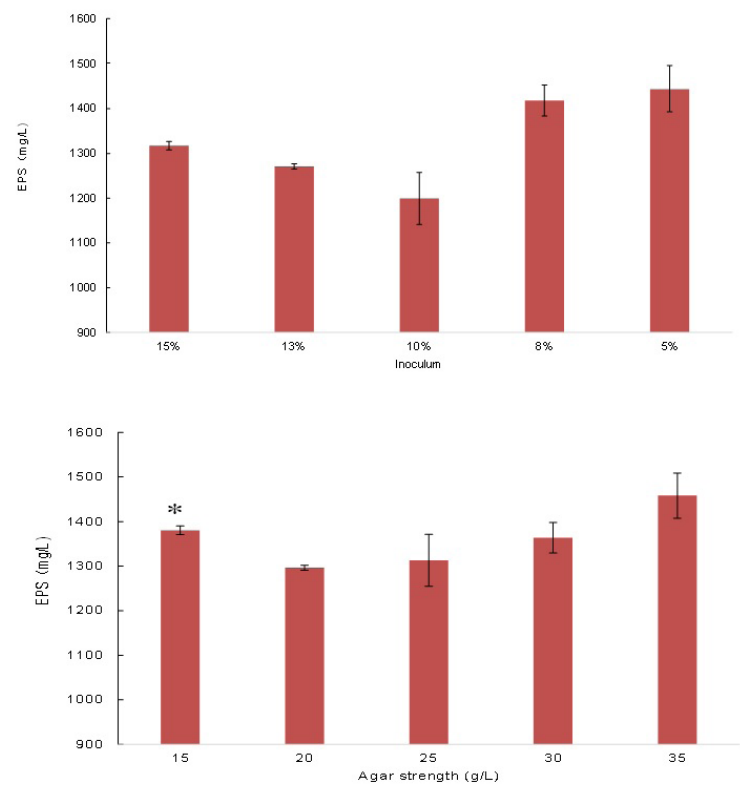

d

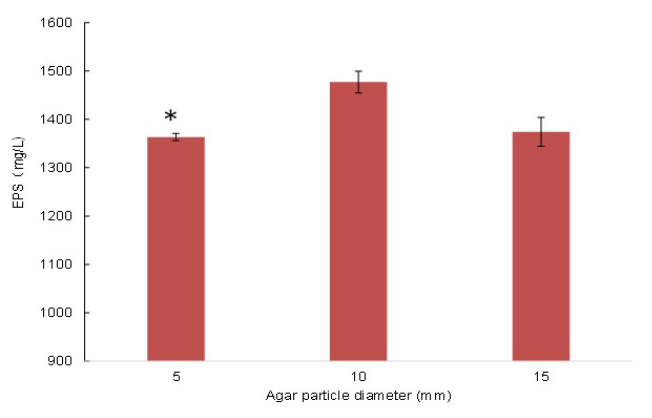

Figure 3. Effect of immobilized materials a temperature b inoculum size c agar strength $\mathrm{d}$ and agar particle diameter e on EPS yield of $L$. plantarum. Significant differences $(p<0.05)$ between the two experimental samples are indicated by the asterisk. 
of LAB was in the order of inoculum size > agar intensity > temperature. The optimum fermentation conditions were agar strength of $30 \mathrm{~g} / \mathrm{L}$, fermentation temperature of $37^{\circ} \mathrm{C}$, and inoculum size of $3 \%$.

Table 1. Orthogonal experimental factors.

\begin{tabular}{cccc}
\hline Factor and level & $\begin{array}{c}\mathrm{A} \\
\text { Agar strength } \\
(\mathrm{mg} / \mathrm{L})\end{array}$ & $\begin{array}{c}\mathrm{B} \\
\text { Temperature } \\
\left({ }^{\circ} \mathrm{C}\right)\end{array}$ & $\begin{array}{c}\mathrm{C} \\
\text { Inoculation } \\
\text { amount }(\%)\end{array}$ \\
\hline 1 & 30 & 35 & 3 \\
2 & 35 & 37 & 5 \\
3 & 40 & 40 & 8 \\
\hline
\end{tabular}

\subsection{Verification through a parallel experiment}

The optimal combination mentioned above were not observed in the orthogonal experiment, therefore, parallel experiments were carried out in triplicate for verification and the results are shown in Figure 4. LAB fermentation was carried out using an inoculum size of $3 \%$ at optimum agar strength of $30 \mathrm{~g} / \mathrm{L}$, at $37^{\circ} \mathrm{C}$. The average yield of EPS in the parallel experiment was $1489.9 \mathrm{mg} / \mathrm{L}$ at $3 \%$ inoculum amount, and $30 \mathrm{~g} / \mathrm{L}$ agar for immobilization at $37^{\circ} \mathrm{C}$.

In this study, we screened six strains of LAB (L. bulgaricus, L. plantarum, L. casei, L. acidophilus, L. lactis subsp. lactis LL9, and L. thermophilus). The highest yield of EPS was $1513.1 \mathrm{mg} / \mathrm{L}$ using a $5 \%$ inoculum of $L$. plantarum fermented at $37^{\circ} \mathrm{C}$ in a shake flask.

Table 2. Orthogonal experiment results.

\begin{tabular}{|c|c|c|c|c|}
\hline $\begin{array}{c}\text { Experiment } \\
\text { Number } \\
\text { Factor }\end{array}$ & $\begin{array}{c}\text { A } \\
\text { Agar strength }(\mathrm{mg} / \mathrm{L})\end{array}$ & $\begin{array}{c}\mathrm{B} \\
\text { Temperature } \\
\left({ }^{\circ} \mathrm{C}\right)\end{array}$ & $\begin{array}{c}\mathrm{C} \\
\text { Inoculum } \\
(\%)\end{array}$ & $\begin{array}{c}\text { Productivity of EPS } \\
(\mathrm{mg} / \mathrm{L})\end{array}$ \\
\hline 1 & 30 & 35 & 3 & 1487.8 \\
\hline 2 & 30 & 37 & 5 & 1418.5 \\
\hline 3 & 30 & 40 & 8 & 1401.5 \\
\hline 4 & 35 & 35 & 5 & 1399.4 \\
\hline 5 & 35 & 37 & 8 & 1399.4 \\
\hline 6 & 35 & 40 & 3 & 1489.9 \\
\hline 7 & 40 & 35 & 8 & 1302.5 \\
\hline 8 & 40 & 37 & 3 & 1485.7 \\
\hline 9 & 40 & 40 & 5 & 1361.5 \\
\hline K1 & 4307.6 & 4189.7 & 4463.4 & \\
\hline K2 & 4288.7 & 4303.6 & 4179.4 & \\
\hline K3 & 4149.7 & 4252.9 & 4103.4 & \\
\hline $\mathrm{K} 1$ & 1435.9 & 1396.6 & 1487.8 & \\
\hline K2 & 1429.6 & 1434.5 & 1393.1 & \\
\hline K3 & 1383.2 & 1417.6 & 1367.8 & \\
\hline $\mathrm{R}$ & 52.7 & 37.9 & 120.0 & \\
\hline
\end{tabular}

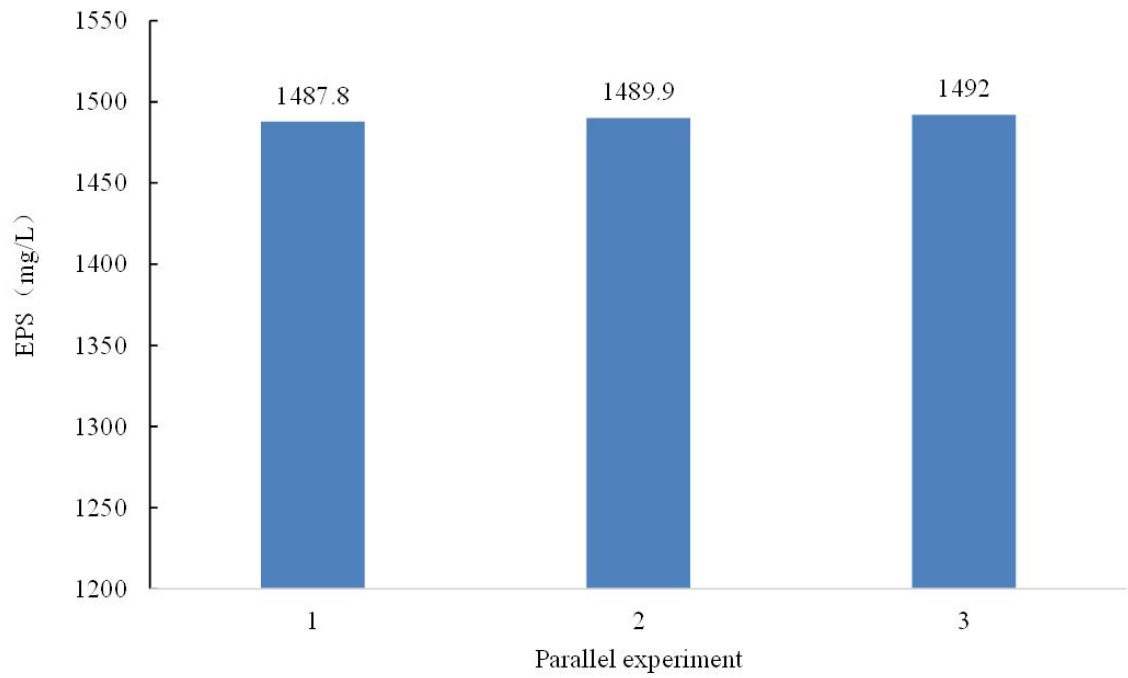

Figure 4. Verification of optimum fermentation condition of LAB through parallel experiments. 
The selection of optimum immobilized carrier for $L$. plantarum was carried out using calcium alginate colloid, carrageenan, gelatin, and agar as the carrier. The agar-embedded method gave the best immobilization effect, and the yield was $1096.2 \mathrm{mg} / \mathrm{L}$. Compared with other immobilization methods, this method has the least impact on EPS yield; therefore, it was selected as the best embedding vector for EPS production by $L$. plantarum.

The process conditions of immobilized fermentation of L. plantarum were studied. The optimum conditions were agar strength $30 \mathrm{~g} / \mathrm{L}$, particle size $1.0 \mathrm{~cm}$, and $3 \%$ inoculum fermentation at $37^{\circ} \mathrm{C}$ for $24 \mathrm{~h}$; the optimum condition gave the highest extracellular polysaccharide yield at $1489.9 \mathrm{mg} / \mathrm{L}$.

\section{Conclusions}

The results reveal that the immobilized cells of $L$. plantarum gave almost the same yield of EPS as that of free cell fermentation, probably because the diffusion of the product in the immobilized carrier was limited, which affected the yield increase. However, from the perspective of the process, the immobilization method greatly simplifies the process. Immobilization reduces the need to activate the strain multiple times, thereby avoiding the step of separating cells in the fermentation liquid, thus simplifying the subsequent product extraction. Moreover, the immobilized LAB cells can be well maintained and can be used repeatedly, effectively increasing the rate of use of the strain and reducing the production cost.

The EPS production of LAB is generally low, and there are many influencing factors. In recent years, based on the understanding of genetic basis, biochemical type, biosynthesis pathway, metabolic model and physiological activity of EPS producing lactic acid bacteria, metabolic engineering method has become a hot spot in this field. The strain and technology of this study also laid a good foundation for the production of EPS by LAB.

\section{Conflict of interest}

None of he authors of this study has any financial interest or conflict with industries or parties.

\section{Availability of data and material}

The datasets used and/or analysed during the current study are available from the corresponding author on reasonable request.

\section{Author contributions}

JT, FYL performed main experiments. JT, FLY, XHH, conceived and designed research. JT, FYL wrote the first draft of the paper. All authors contributed to discussing the results and editing the paper. All authors approved the final manuscript.

\section{Acknowledgements}

This research was supported by the Zhengzhou University of Light Industry Research Scholarship in 2014 (project No. 2014XJJ005).

\section{References}

Abedfar, A., \& Hossininezhad, M. (2016). Overview of the most important characterization of exopolysaccharides produced by probiotics bacteria and their biological function. Journal of Environmental Science, Toxicology and Food Technology, 10(11), 47-55.

Abid, Y., Casillo, A., Gharsallah, H., Joulak, I., Lanzetta, R., Corsaro, M. M., Attia, H., \& Azabou, S. (2018). Production and structural characterization of exopolysaccharides from newly isolated probiotic lactic acid bacteria. International Journal of Biological Macromolecules, 108, 719-728. http://dx.doi.org/10.1016/j.ijbiomac.2017.10.155. PMid:29080817.

Caggianiello, G., Kleerebezem, M., \& Spano, G. (2016). Exopolysaccharides produced by lactic acid bacteria: from health-promoting benefits to stress tolerance mechanisms. Applied Microbiology and Biotechnology, 100(9), 3877-3886. http://dx.doi.org/10.1007/s00253-016-7471-2. PMid:27020288.

Darilmaz, D. O., \& Beyatli, Y. (2012). Investigating hydrophobicity and the effect of exopolysaccharide on aggregation properties of dairy propionibacteria isolated from Turkish homemade cheeses. Journal of Food Protection, 75(2), 359-365. http://dx.doi.org/10.4315/0362028X.JFP-11-225. PMid:22289598.

Deepak, V., Pandian, S. R. K., Sivasubramaniam, S. D., Nellaiah, H., \& Sundar, K. (2016). Optimization of anticancer exopolysaccharide production from probiotic Lactobacillus acidophilus by response surface methodology. Preparative Biochemistry \& Biotechnology, 46(3), 288-297. http://dx.doi.org/10.1080/10826068.2015.103138 6. PMid:25831127.

Dilna, S. V., Surya, H., Aswathy, R. G., Varsha, K. K., Sakthikumar, D. N., Pandey, A., \& Nampoothiri, K. M. (2015). Characterization of an exopolysaccharide with potential health-benefit properties from a probiotic Lactobacillus plantarum RJF4. Food Science and Technology, 64, 1179-1186.

El-Dalatony, M. M., Kurade, M. B., Abou-Shanab, R. A. I., Kim, H., Salama, E., \& Jeon, B. (2016). Long-term production of bioethanol in repeated-batch fermentation of microalgal biomass using immobilized Saccharomyces cerevisiae. Bioresource Technology, 219, 98-105. http://dx.doi.org/10.1016/j.biortech.2016.07.113. PMid:27479800.

Eş, I., Khaneghah, A. M., Barba, F. J., Saraiva, J. A., Sant’Ana, A. S., \& Hashemi, S. M. B. (2018). Recent advancements in lactic acid production - a review. Food Research International, 107, 763-770. http://dx.doi.org/10.1016/j.foodres.2018.01.001. PMid:29580545.

Harutoshi, T. (2013). Exopolysaccharides of lactic acid bacteria for food and colon health applications. In M. Kongo (Ed.), Lactic acid bacteria: $R$ \& $D$ for food, health and livestock purposes. Croatia: InTech. Retrieved from https://sci-hub.se/10.5772/50839.

Idris, A., \& Suzana, W. (2006). Effect of sodium alginate concentration, bead diameter, initial $\mathrm{pH}$ and temperature on lactic acid production from pineapple waste using immobilized Lactobacillus delbrueckii. Process Biochemistry, 41(5), 1117-1123. http://dx.doi.org/10.1016/j. procbio.2005.12.002.

Imran, M. Y. M., Reehana, N., Jayaraj, K. A., Ahamed, A. A. P., Dhanasekaran, D., Thajuddin, N., Alharbi, N. S., \& Muralitharan, G. (2016). Statistical optimization of exopolysaccharide production by Lactobacillus plantarum NTMI05 and NTMI20. International Journal of Biological Macromolecules, 93(Part A), 731-745. http:// dx.doi.org/10.1016/j.ijbiomac.2016.09.007. PMid:27601132.

Ishiguro, S., Uppalapati, D., Goldsmith, Z., Robertson, D., Hodge, J., Holt, H., Nakashima, A., Turner, K., \& Tamura, M. (2017). Exopolysaccharides extracted from Parachlorella kessleri inhibit colon carcinoma growth in mice via stimulation of host antitumor 
immune responses. PLoS One, 12(4), e0175064. http://dx.doi. org/10.1371/journal.pone.0175064. PMid:28380056.

Kanak, E. K., \& Yilmaz, S. O. (2021). Identification, antibacterial and antifungal effects, antibiotic resistance of some lactic acid bacteria. Food Science and Technology, 41(Suppl. 1), 174-182. http://dx.doi. org/10.1590/fst.07120.

Kleerebezem, M., Kuipers, O. P., \& Smid, E. J. (2017). Editorial: lactic acid bacteria-a continuing journey in science and application. FEMS Microbiology Reviews, 41(Suppl. 1), S1-S2. http://dx.doi.org/10.1093/ femsre/fux036. PMid:28830097.

Korcz, E., Kerényi, Z., \& Varga, L. (2018). Dietary fibers, prebiotics, and exopolysaccharides produced by lactic acid bacteria: potential health benefits with special regard to cholesterol-lowering effects. Food \& Function, 9(6), 3057-3068. http://dx.doi.org/10.1039/ C8FO00118A. PMid:29790546.

Lee, I., Caggianiello, G., Van Swam, I. I., Taverne, N., Meijerink, M., Bron, P. A., Spano, G., \& Kleerebezem, M. (2016). Strain-specific features of extracellular polysaccharides and their impact on lactobacillus plantarum-host interactions. Applied and Environmental Microbiology, 82(13), 3959-3970. http://dx.doi.org/10.1128/AEM.00306-16. PMid:27107126.

Lee, S., Kim, J., Jung, Y., Park, S., Shin, W., Park, C., Hong, S., \& Kim, G. (2011). Composition of organic acids and physiological functionality of commercial Makgeolli. Korean Journal of Food Science Technology, 43(2), 206-212. http://dx.doi.org/10.9721/KJFST.2011.43.2.206.

Mejia-Gomez, C. E., \& Balcázar, N. (2020). Isolation, characterisation and continuous culture of Lactobacillus spp. and its potential use for lactic acid production from whey. Food Science and Technology, 40(4), 1021-1028. http://dx.doi.org/10.1590/fst.29619.

Menchavez, R. N., \& Ha, S. H. (2019). Fed-batch acetone-butanol-ethanol fermentation using immobilized Clostridium acetobutylicum in calcium alginate beads. Korean Journal of Chemical Engineering, 36(6), 909-913. http://dx.doi.org/10.1007/s11814-018-0232-z.

Miao, M., Ma, Y., Huang, C., Jiang, B., Cui, S. W., \& Zhang, T. (2015). Physicochemical properties of a water soluble extracellular homopolysaccharide from Lactobacillus reuteri SK24.003. Carbohydrate Polymers, 131, 377-383. http://dx.doi.org/10.1016/j. carbpol.2015.05.066. PMid:26256197.

Mozzi, F., Giori, G. S., \& Valdez, G. F. (2003). UDP-galactose 4-epimerase: a key enzyme in exopolysaccharide formation by Lactobacillus casei CRL 87 in controlled $\mathrm{pH}$ batch cultures. Journal of Applied Microbiology, 94(2), 175-183. http://dx.doi.org/10.1046/j.13652672.2003.01821.x. PMid:12534808.
Oleksy, M., \& Klewicka, E. (2018). Exopolysaccharides produced by Lactobacillus sp.: biosynthesis and applications. Critical Reviews in Food Science and Nutrition, 58(3), 450-462. PMid:27246190.

Patel, S., Majumder, A., \& Goyal, A. (2012). Potentials of Exopolysaccharides from lactic acid bacteria. Indian Journal of Microbiology, 52(1), 3-12. http://dx.doi.org/10.1007/s12088-011-0148-8. PMid:23449986.

Pato, U., Riftyan, E., Ayu, D. F., Jonnaidi, N. N., Wahyuni, M. S., Feruni, J. A., \& Abdel-Wahhab, M. A. (2021). Antibacterial efficacy of lactic acid bacteria and bacteriocin isolated from Dadih's against Staphylococcus aureus. Food Science and Technology. Ahead of print. http://dx.doi. $\operatorname{org} / 10.1590 /$ fst. 27121 .

Riaz, M. S., Shaheen, T., Batool, N., Saleem, S., \& Hayat, F. (2015). Lactic acid bacteria as probiotic candidate and their application. Journal of Biology and Today's World, 4, 209-216.

Ryan, P. M., Ross, R. P., Fitzgerald, G. F., Caplice, N. M., \& Stanton, C. (2015). Sugar-coated: exopolysaccharide producing lactic acid bacteria for food and human health applications. Food \& Function, 6(3), 679-693. http://dx.doi.org/10.1039/C4FO00529E. PMid:25580594.

Saadat, Y. R., Khosroushahi, A. Y., \& Gargari, B. P. (2019). A comprehensive review of anticancer, immunomodulatory and health beneficial effects of the lactic acid bacteria exopolysaccharides. Carbohydrate Polymers, 217, 79-89. http://dx.doi.org/10.1016/j.carbpol.2019.04.025. PMid:31079688.

Sanalibaba, P., \& Çakmak, G. A. (2016). Exopolysaccharides production by lactic acid bacteria. Applied Microbiology: Open Access, 2(2), 1000115

Surayot, U., Wang, J., Seesuriyachan, P., Kuntiya, A., Tabarsa, M., Lee, Y., Kim, J., Park, W., \& You, S. (2014). Exopolysaccharides from lactic acid bacteria: structural analysis, molecular weight effect on immunomodulation. International Journal of Biological Macromolecules, 68, 233-240. http://dx.doi.org/10.1016/j.ijbiomac.2014.05.005. PMid:24820155.

Thakur, A., Panesar, P. S., \& Saini, M. S. (2019). L(+)-Lactic acid production by immobilized lactobacillus casei using low cost agro-industrial waste as carbon and nitrogen sources. Waste and Biomass Valorization, 10(5), 1119-1129. http://dx.doi.org/10.1007/ s12649-017-0129-1.

Thummar, V. D., \& Ramani, V. M. (2016). Recent application of lactic acid bacteria as source of industrially important compounds. Journal of Pure \& Applied Microbiology, 10, 10497-10506.

Zhang, Y. L., Hu, P., Wang, J. L., \& Liao, Q. W. (2015). Isolation of exopolysaccharides-producing lactic acid bacteria and its antioxidant properties. China Brewing, 34, 37-42. 